\title{
LUTERO E A TRADUÇÃO DO SAGRADO*
}

Furio Jesi

De 1522 a 1534, Lutero realiza a primeira tradução completa da Bíblia em língua alemã. Nos mesmos anos ele escreveu um Sendbrief vom Dolmetschen (Epístola sobre a tradução) em que expõe os princípios fundamentais da sua teoria da tradução, as regras que ele próprio tinha procurado seguir e que todo futuro tradutor deveria procurar seguir. É notório que a tradução de Lutero assinala, por assim dizer, o nascimento da língua alemã moderna. Mas é necessário não esquecer que também seu Sendbrief vom Dolmetschen constitui uma contribuição importante à teoria da tradução em relação a qual, no âmbito da cultura alemã, talvez só podem ser aproximadas, no que diz respeito à importância, as notas de Goethe ao Divan e as considerações de Walter Benjamin em torno ao que ele disse ser "a tarefa do tradutor". É necessário não esquecer, em suma, que, ao menos no caso da cultura alemã, um complexo de circunstâncias históricas fez coincidir em um único momento tanto a estreia literária da língua moderna quanto uma das provas mais profundas e mais ricas de consequências da reflexão sobre o próprio conceito de tradução.

Lutero escrevia no século XVI e dedicava suas reflexões acima de tudo, senão de modo exclusivo, não à tradução em geral, mas à tradução do que considerava texto sagrado, palavra mesma de Deus. Para nós, laicos, e laicos do século XX, é extremamente difícil colocar-se naquela dimensão temporal e

Lutero e la traduzione del sacro.

Nuova corrente, Genova, anno 56, n. 143, p. 175-182, 2009.

Tradução de Vinícius Nicastro Honesko.

* O texto inédito que aqui apresentamos, graças à cortesia de Marta Rossi Jesi, conservou-se entre os papéis de Jesi numa pequena pasta com 9 páginas datilografadas (formato $28 \mathrm{~cm} \mathrm{X}$ $22 \mathrm{~cm}$ ), numeradas, com poucas correções e acréscimos colocados a mão, sem título. Como outros já publicados no número monográfico, organizado por G. Agamben e A. Cavalletti, da revista Cultura Tedesca (n. 12,1999), e assinaladamente na quinta seção dos inéditos, o ensaio faz parte dos materiais selecionados para a reconstrução do volume, projetado por Jesi por volta da metade dos anos setenta e nunca terminado, Traduzione e duplicità dei linguaggi. Para uma datação aproximativa podemos nos referir ao "Prefácio" de Esoterismo e linguaggio mitologico, escrito em junho de 1976, no qual Jesi anuncia a publicação do trabaIho em curso. (Andrea Cavalletti) 
cultural ao ponto de perceber na sua atualidade específica e única, na sua originária forma viva, a experiência de Lutero tradutor e teórico da tradução. Podemos, no entanto, recuperar ao menos um indício da audácia dessa experiência ao confrontar as palavras do Sendbrief com aquelas propostas pelos calvinistas de Genebra, em 1535, à sua tradução da Bíblia para o francês.

Os calvinistas genebreses escrevem:

No que diz respeito aos hebraísmos, traduzimos palavra por palavra os que têm uma sua particular evidência, que não podem ser bem traduzidos à nossa língua de outro modo e que, em relação a esta, todavia não são tão distantes ao ponto de torná-la obscura.

\section{Diz Lutero por sua vez:}

Não é preciso pedir às palavras latinas para ensinar-vos como se pode falar o alemão. É preciso dirigir-se à mãe na casa, às crianças na rua, ao homem comum no mercado, observar como a sua boca fala e traduz respeitando seu ensinamento, porque apenas assim eles vos compreenderão e terão a sensação de que a eles estais falando em alemão.

Seria temerário a partir disso deduzir que Lutero nutrisse menor respeito do que os calvinistas pela sacralidade do texto por traduzir, ou que os calvinistas se abandonassem mais do que Lutero à intervenção de Deus, que os teria iluminado, segundo seu agrado - como eles afirmam - na atividade de tradutores. Para Lutero, o ditado da Bíblia não era menos palavra de Deus do que para os calvinistas; e, não menos do que os calvinistas, Lutero confiava no socorro iluminador de Deus enquanto realizava sua tradução. Antes, talvez seria possível procurar verificar historicamente se existiram diferenças de caráter social entre as modalidades e os objetivos do apostolado calvinista e os do apostolado luterano, dado ser possível que a insistência de Lutero sobre a necessidade de dispor de uma Bíblia percebida como palavra de Deus em alemão pela "mãe na casa", pelas "crianças na rua", pelo "homem comum no mercado", implicasse o desejo de fazer chegar a palavra de Deus, superando os obstáculos culturais, às pessoas que estivessem nos estratos mais baixos da escala social, enquanto a tradução calvinista, com os seus hebraísmos "traduzidos palavra por palavra", teria sido acessível a pessoas de condições sociais um pouco mais elevadas e de formação cultural um pouco mais erudita.

Mas é certo que a tradução da Bíblia de Lutero, sempre nas suas intenções 
e quase sempre nos fatos, deu a quem quer que a leu ou a escutou a "impressão de que lhes [eles próprios] falava alemão"; enquanto a tradução dos calvinistas genebreses, menos do que discorrer no leito das locuções de língua francesa familiares a qualquer estrato social, acabou por impor a adoção, por parte das pessoas de mais modesta ou de nenhuma formação erudita, de hebraísmos (e de grecismos) antes jamais ouvidos e destinados a sobreviver com as conotações impressas por essa particular matriz, quando também passaram a fazer parte da linguagem cotidiana de comunidades para as quais eventos e locuções profanas eram constantemente entrelaçados com eventos e locuções sagradas. Em resumo, no calvinismo dos países de língua francesa as locuções adquiridas de maneira peculiar a partir da tradução genebresa da Bíblia conservaram sempre, ou por muito tempo, as características de citações de uma linguagem heterogênea em relação à cotidiana. Não por acaso, no mais, uma tradição crítica que possui um fundo de verdade faz remontar apenas ao século XVII, e a um autor católico e não calvinista como Pascal, a estreia do francês moderno. E não por acaso, repetimos, justo a Pascal: portanto, a um católico, sim, mas a um católico que traduziu na linguagem cotidiana as asperezas dos hebraísmos e dos grecismos da Bíblia genebresa, assim como - por assim dizer - traduziu na própria experiência do catolicismo componentes relevantes da experiência calvinista. Essa homogeneidade entre língua sagrada e língua cotidiana, promovida por Pascal, foi então o pressuposto, não muito remoto, graças ao qual as afinidades de ideologia e de experiência religiosa entre Rousseau e o pietismo alemão encontraram seu correspondente nas afinidades entre a linguagem rousseauniana e aquela que Langen definiu o "Wortschatz", o "patrimônio lexical", de matriz luterana, do pietismo alemão. Tanto o "Wortschatz" de Rousseau quanto o do pietismo alemão são compostos não por vocábulos incomuns "na casa", "na rua", "no mercado", mas por vocábulos costumeiros das ocasiões cotidianas e profanas, que, de acordo com o uso que deles se faz, dos tempos e dos lugares em que ressoam, adquirem conotações ou ecos sagrados.

Lutero, portanto, e nisso se revela um aspecto da sua originalidade, exerceu a integração imediata da língua apropriada ao sagrado com a língua, o alemão, apropriada ao profano, reconhecendo nesta última a absoluta disponibilidade objetiva para tornar-se veículo da palavra de Deus; e o fez colocando as bases de uma teoria da tradução que seria revelada tão determinante no âmbito da cultura alemã ao ponto de adquirir - configurada na 
perspectiva dos historiadores e dos linguistas modernos - as características de única e antiga contraparte suficientemente autorizada da correlação teórico-prática de Voss, de Goethe, de Schlegel, de Tieck, de Hölderlin, ou, em tempos já mais próximos a nós, de George, de Rudolf Pannwitz, de Karl Kraus e de Walter Benjamin.

Dissemos: integração imediata de uma língua apropriada ao sagrado com uma língua apropriada ao profano. Se invertermos os termos, isto é, pensarmos uma integração imediata de uma língua apropriada ao profano com uma língua apropriada ao sagrado, encontramo-nos diante de uma situação em que, segundo um exemplo com frequência citado pelo meu mestre Karoly Kerényi, estava, quase por acaso, Sir George Grey, um funcionário da administração colonial britânica nomeado, em 1845, governador da Nova Zelândia. Em 1855 Sir George publicou um volume dedicado, como diz o titulo, à "mitologia polinésia e à antiga história tradicional da população da nova Zelândia". Não era costumeiro, e podia até parecer uma extravagância, que um governador colonial se dedicasse a pesquisas do gênero. No prefácio do seu livro, com efeito, Sir George readquire o aprumo do funcionário britânico, explicando ter empreendido tal obra não tanto por razões eruditas quanto pelo fato de the ter sido necessária para cumprir escrupulosamente o seu mandato, isto é, para entender-se bem com aqueles que definem "os súditos indígenas de Sua Majestade". Aconteceu isto: na sua chegada à Nova Zelândia, Sir George recorrera apenas aos intérpretes, mas se deu conta de que desse modo era dificilíssimo conversar com os indígenas. Então, afrontou a dificuldade de estudar pessoalmente a língua dos indígenas. Nova desilusão: mesmo assim não conseguia compreender com clareza os discursos dos chefes indígenas com os quais necessariamente tinha que lidar.

Constatei - ele escreve - que esses chefes, para explicar suas opiniões ou intenções, falando ou por escrito, citavam ou aludiam a antigos poemas ou provérbios fundados sobre um antigo sistema mitológico; e enquanto as partes mais importantes das suas comunicações estavam revestidas de tal forma metafórica, os interpretes era incapazes e mal conseguiam (quando o conseguiam) traduzir os poemas ou explicar as alusões.

Sir George, que durante cerca de dez anos pôs-se a recolher e a entender os materiais das traduções mitológicas neozelandesas, a partir delas constituiu uma espécie de corpus e só então teve a percepção de conseguir de fato se 
entender com os seus interlocutores. Naturalmente, suas conversas com os chefes indígenas eram sobretudo de caráter diplomático e versavam sobre questões de governo da colônia: portanto, sobre argumentos em absoluto profanos. Quis debruçar-me por um momento sobre a auto-justificação que Sir George expõe no prefácio, justo por que não há dúvidas sobre os objetivos da sua pesquisa no âmbito da mitologia neozelandesa. Ele, se não de modo ocasional, não fez das experiências religiosas dos indígenas objeto de suas conversas com eles, mas apenas dos problemas profanos surgidos do fato de serem eles "os súditos indígenas de Sua Majestade Britânica". E não há dúvida de que, estudando a mitologia neozelandesa, ele permanecesse absolutamente estranho à experiência da sacralidade que acompanhava, para os indígenas, as imagens mitológicas evocadas. Ele quis operar a integração imediata de uma língua apropriada ao profano, isto é, o inglês das suas ordenações, dos seus regulamentos, da sua própria forma mentis de funcionário de governo, com uma língua apropriada ao sagrado, isto é, a língua neozelandesa usada pelos seus interlocutores: língua apropriada ao sagrado, plena de evocações mitológicas, e, nisso, profundamente diversa da artificiosa língua neozelandesa que se podia aprender ao se ignorar as tradições e poemas; e também língua viva, falada, operante na sua inteireza de estratos semânticos.

Se, como dissemos, Lutero realizou a tradução de uma língua portadora do sagrado e não mais falada (ou somente artificiosamente falada), como a da Bíblia, em uma língua profana e falada, Sir George Grey realizou a tradução de uma língua profana em uma língua portadora do sagrado. Essa simetria poderia não parecer tal a quem objetasse que, no caso de Lutero, houve a instituição de uma relação entre uma língua não falada (a da Bíblia) e uma língua falada, enquanto no caso de Sir George Grey a relação foi instituída entre duas línguas faladas (o inglês do século XIX e o neozelandês). Mas é preciso observar que de fato a simetria existe, porque a distância histórico-cultural entre o inglês do século XIX e o neozelandês é homóloga à distância entre o silêncio da língua da Bíblia no século XVI e o ressoar da língua alemã "na casa", "na rua" e "no mercado" naquele mesmo século.

A simetria entre o caso de Lutero e o de Sir George Grey, colocando em evidência as atuações de duas relações em sentido inverso entre língua mitológica portadora do sagrado e língua profana, pede algumas reflexões sobre as relações entre tradução e mitologia. No primeiro caso, o de Lutero, pode-se dizer que a língua profana permitiu a atualização de imagens mitológicas e 
sagradas, enquanto no segundo, o de Sir George Grey, a língua mitológica e sagrada permitiu a atualização de imagens profanas. Lutero propunha-se a fazer ressoar a própria palavra de Deus, mesmo quando se exprimia de modo a dar aos alemães a impressão de que Ihes falava em alemão; Sir George Grey propunha-se a cumprir escrupulosamente seu mandato profano, quando também se exprimia, ou deixava que os outros se exprimissem, de modo que os neozelandeses tivessem a impressão de ouvir e de fazer ressoar sua língua mitológica e sagrada. A mitologia exprimiu-se em língua profana; a profanidade se exprimiu em língua mitológica. Em ambos os casos realizou-se uma tradução. Em ambos os casos a relação em que consistiu a tradução pode ser configurada, acima de tudo, como uma relação dialética entre mitologiasacralidade e profanidade; e resta ver se no âmbito de tal relação em aparência dialética houve verdadeiramente um momento de síntese: se Lutero e Sir George Grey cumpriram verdadeiramente aquela que, nas suas intenções, era, como dissemos, uma integração.

O problema que agora queremos circunscrever não é, entretanto, de imediato aquele, específico, dos êxitos das operações de Lutero e de Sir George Grey como tradutores, mas sim aquele, muito mais amplo, da eventualidade de que toda tradução estabeleça uma relação entre dois âmbitos linguísticos cuja estranheza inicial seja homóloga à estranheza entre uma língua mitológico-sagrada e uma língua profana. Nosso objetivo imediato é, no entanto, afrontar esse problema, ou, ainda e de modo mais preciso, essa hipótese de trabalho, à luz e no âmbito da documentação que pertence à cultura alemã. Essa escolha de campo não é ocasional ou excessivamente arbitrária, ao se pensar que é na cultura alemã que se colocam algumas das contribuições mais significativas à teoria da tradução na Europa moderna. Partimos de Lutero, e é notória a importância que tiveram, também fora da Alemanha, a experiência e a reflexão teórica de Lutero tradutor. Depois de Lutero nomeamos Hölderlin, Tieck, Schlegel e, portanto, acenamos para um arco de experiências e reflexões teóricas de tradutores que passa pelo Romantismo alemão; e também aqui é notório o peso que tiveram as doutrinas e as experiências alemãs no quadro heterogêneo dos Romantismos europeus. $O$ arco se concluía com Walter Benjamin, de quem também é notória a importância, europeia, como pensador e teórico da filosofia da linguagem.

No mais, o fato de que nos voltemos em específico à cultura alemã para afrontar a teoria da tradução dentro de uma problemática tal que envolva 
tradução e mitologia, é também motivado por algumas precisas razões inerentes à história da língua alemã. Expondo brevemente essas razões, solidárias com alguns dos elementos mais substanciais e enigmáticos da filologia germânica, começaremos a entrar, ao mesmo tempo, no coração dessa problemática. 